\title{
O DESIGNER COMO PROMOTOR DE UM DESENVOLVIMENTO SUSTENTÁVEL: UMA RELEITURA DA LEGISLAÇÃO AMBIENTAL BRASILEIRA
}

THE DESIGNER AS A PROMOTER FOR SUSTAINABLE DEVELOPMENT: A FRESH READING OF BRAZILIAN ENVIRONMENTAL LEGISLATION

\section{Maria Clara Schuler Chedid (UFRGS); Jocelise Jacques de Jacques, Dra. (UFRGS)}

\section{Palavras Chave}

Legislação Ambiental; Política Ambiental; Design; Desenvolvimento Sustentável de Produto; Sustentabilidade

\section{Key Words}

Environmental Legislation; Environmental Policies; Design; Sustainable Product Development; Sustainability

\section{RESUMO}

O artigo apresenta uma discussão sobre o conceito de sustentabilidade, abordado na legislação ambiental, e o potencial do designer como promotor de medidas de sustentabilidade social e ambiental no processo de desenvolvimento e na produção de produtos, no contexto internacional e nacional. A pesquisa faz parte do projeto "Estudo de Métricas de Sustentabilidade Ambiental e Social no Processo de Desenvolvimento de Produtos", e foi realizada a partir de revisão bibliográfica em artigos acadêmicos sobre Direito Ambiental, bem como na investigação da própria legislação, e de textos que abordam os temas design e sustentabilidade, incluindo uma discussão sobre o conceito de meio ambiente e como ele é apresentado na Constituição de 1988. Também se faz um apanhado dos principais marcos de discussão da questão ambiental em nível mundial, principalmente os eventos promovidos pelas Nações Unidas, e seus frutos na evolução da legislação ambiental. Por fim, relaciona-se o cenário de busca por inovação e sustentabilidade à prática profissional do designer, a fim de destacar o seu importante papel nesse processo.

\section{ABSTRACT}

The article presents a discussion about the concept of sustainability, as approached by environmental legislation, and the professional designer's potential of promoting initiatives and measures towards social and environmental sustainability product development and production, both in national and international contexts. This research is part of a larger project entitled "Study of Environmental and Social Sustainability Metrics in the Product Development Process", and it is based on a literature review of academic articles about environmental law, on the environmental legislation itself, and on texts about design and sustainability, including a discussion on the concept of environment and how it is understood in the Brazilian Constitution. A review of the main milestones on the discussion of the environmental issues in a global scale, particularly the UN conferences on climate and environment, and their influence over the evolution of environmental legislation. In this context, the search for innovation and sustainability is related to the professional practice of designers, in order to highlight its important contribution in this process. 


\section{INTRODUÇÃO}

O presente artigo relata a fase inicial de uma pesquisa de iniciação científica que faz parte do projeto denominado "Estudos de Métricas de Sustentabilidade Ambiental e Social no Processo de Desenvolvimento de Produtos", iniciado em 2013, que atualmente está contemplado na linha de Pesquisa Design Emoção e Sustentabilidade, dentro do Programa de Pós-Graduação em Design da Universidade Federal do Rio Grande do Sul. Neste projeto entende-se que o impacto ambiental relacionado à exploração de recursos naturais e às emissões de carbono pode ser considerado um problema decorrente do fluxo linear de produção-consumo. Reconhecer a necessidade de mudança é tão importante quanto investigar formas de viabilizá-la. Para isto, acredita-se que uma das áreas em que se devem concentrar esforços é na concepção e no desenvolvimento de produtos e processos produtivos (HAWKEN, LOVINS et al., 1999; MCDONOUGH e BRAUNGART, 2002).

Muitos produtos recebem o título de "eco" ou "sustentável", porém questiona-se: o quão melhores são esses produtos? E até que ponto a sustentabilidade ambiental e/ou social realmente pautou seu processo de projeto? Para responder estas questões, um dos objetivos iniciais do estudo é identificar como a legislação tem influenciado transformações no projeto de produtos.

A pesquisa encontra-se em fase inicial e seu foco, nesta etapa, está na compreensão das características e dos princípios que norteiam a legislação ambiental brasileira, além da construção de uma perspectiva histórica, relacionando o cenário nacional aos avanços ocorridos em outros países. Para tanto, é realizada uma revisão bibliográfica em artigos acadêmicos sobre Direito Ambiental e design sustentável, bem como na legislação brasileira pertinente e em textos sobre sustentabilidade divulgados por empresas. Nesta tarefa buscou-se, também, transcrever uma linguagem de legislação, que não é familiar aos designers, para que a compreensão de sua evolução possa influenciar os projetistas a desenvolverem produtos melhores, ambiental, social e economicamente. Este primeiro estudo foi realizado com intuito de que, na segunda etapa da pesquisa, seja feito um levantamento de leis que possam ter interferido diretamente na composição e nos processos de produção de produtos dentro das dimensões de sustentabilidade.

\section{ESTRATÉGIAS DE PESQUISA}

Vários fatores colaboram para a transformação do desenvolvimento de produtos rumo à inclusão das diversas dimensões do conceito de sustentabilidade, com ênfase na dimensão ambiental e na legislação como um dos fatores propulsores de mudanças do design de produtos. Para entender estes fatores, as atividades iniciais desta pesquisa são referentes ao levantamento de legislações ambientais do Brasil, de alguns países da Europa e da América do Norte (destino de exportação de muitos dos nossos produtos), a partir de 1990. Num segundo momento da pesquisa, o qual não é do escopo deste artigo, têm-se o intuito de identificar mudanças ocorridas, correlacionando alterações resultantes nos produtos, relativas à seleção de materiais ou concepção da solução projetual, às legislações implantadas.

A pesquisa bibliográfica inicial foi realizada em publicações de duas áreas distintas: (i) direito ambiental e (ii) design. Como o levantamento foi realizado por pesquisadores com formação em Design, utilizou-se textos básicos da área do Direito, como a Constituição Federal Anotada, de Uadi Lammêgo Bulos, para a compreensão inicial dos conceitos, e, posteriormente, para reconhecer as discussões sobre as questões ambientais na visão dos profissionais, foram consultados vários artigos do portal "âmbito-jurídico.com.br".

A terceira fonte para a revisão de literatura foram artigos acadêmicos, bem como relatórios divulgados por empresas, relacionados aos temas: legislação ambiental, produtos ambientalmente amigáveis, produtos sustentáveis, green design e green products.

A seguir, é descrito o resultado desta primeira fase do levantamento bibliográfico, que enfoca a importância da compreensão do conceito de meio ambiente, explorando desde a dimensão física do conceito até a forma como a sociedade se coloca em relação à natureza, discussão contemplada do item 3 do presente artigo. Posteriormente, é feito o relato da evolução do direito ambiental no mundo e sua construção no Brasil. Tais temas embasam a discussão sobre a importância do papel do designer na aproximação entre o processo de produção industrial e ações ambientalmente orientadas.

\section{DIFERENTES ABORDAGENS DO CONCEITO DE MEIO AMBIENTE}

O termo meio ambiente não conta com uma definição universal, tendo em vista que autores realizam análises sob diferentes perspectivas. As diversidades encontradas na interpretação do termo se dão pelas concepções éticas que permearam o pensamento humano no decorrer do tempo.

No Dicionário Aurélio da Língua Portuguesa (2010), ambiente é definido como "aquilo que cerca ou envolve os seres vivos ou as coisas, por todos os lados". Nesta 
definição é explorado um entendimento de meio ambiente somente pelo seu aspecto físico. Porém, analisando de forma mais aprofundada, o conceito pode englobar questões mais complexas que apenas uma definição espacial e material do tema.

Quando refletimos sobre a relação entre as organizações humanas dentro da biosfera, devemos empregar o termo ambientalismo, ou seja, o estudo das interações entre sociedade, tecnologia e meio ambiente natural (CLEGG, HARDY et al., 1996). Pode-se afirmar que este conceito de ambientalismo fundamentou três abordagens principais para definir a relação humano-meio ambiente: o ambientalismo radical, o paradigma social dominante e o ambientalismo renovado.

O ambientalismo radical defende a mudança de objetivo na busca científica e tecnológica para reduzir a intervenção do ser humano no ambiente natural, incentivando uma postura anticonsumista e antimaterialista como conduta apropriada em um mundo com recursos limitados e que vêm sendo exauridos. Esta abordagem, referida também por ecologia profunda, fundamenta-se em uma visão sistêmica, na qual se reconhece a interdependência entre todos os fenômenos; assim, indivíduos e sociedades estão inseridos como dependentes dos processos cíclicos da natureza (CAPRA, 1998). Este entendimento é compartilhado pelo biocentrismo, que integra o homem à natureza, configurando uma relação de interdependência das duas partes. Linhas de pensamento como esta dão margem para a discussão de um comportamento mais integrado na relação homem e natureza, como pode ser visto nas palavras de Carvalho (2004) ao dizer que "o meio ambiente é concebido pelas relações humano-natureza, em constante interação, e, dessa forma, o ser humano passa a ser integrante do meio e torna-se um agente participativo e transformador de seu meio".

Ressalta-se, também, a forma mais profunda da relação homem e meio ambiente, que se encontra na vertente do ecocentrismo, teoria político-filosófica advinda da ecologia, na qual se percebe a necessidade da proteção dos seres vivos e do meio abiótico, garantindo o equilíbrio dos ecossistemas. Uma postura ecocêntrica recentemente adotada pelo governo do Equador e da Bolívia foi a de reconhecer os direitos do meio ambiente enquanto lugar onde se realiza a vida e a inclusão do conceito de Bem Viver em suas respectivas Constituições.

Em oposição ao ecocentrismo, existe o antropocentrismo, paradigma social dominante, o qual remonta à Antiguidade e chega ao lluminismo e à Revolução Industrial, e define o ser humano como dominador do meio ambiente, estando a natureza a seu serviço (CLEGG, HARDY et al., 1996). Pode-se afirmar que este é o pensamento que mais vigorou na consciência coletiva durante a história, com a ideia do homem como medida para todas as coisas. Originário das filosofias gregas, o antropocentrismo traz a visão de que é preciso garantir o bem-estar do ser humano que, para isso, apropria-se dos bens ambientais para seu uso. Nesta vertente, é possível perceber a dissociação entre o homem e a natureza: ela existe para atender às necessidades humanas.

A Constituição Federal brasileira possui um "antropocentrismo alargado" (LEITE 2010 apud PESSOA e BARRETO, 2013). Este pensamento conjuga os seres vivos sem uma relação de superioridade, estabelecendo a proteção, por parte da humanidade, dos ecossistemas para gerações futuras. Num cenário otimista, pode-se entender este viés semelhante à abordagem mediadora entre os extremos acima citados (ecocentrismo e antropocentrismo), configurada pelo ambientalismo renovado. Segundo esta abordagem, a tecnologia deve servir ao progresso científico, econômico, e para prever e solucionar riscos ambientais; assim o meio natural deve influenciar as decisões industriais. Pode-se afirmar que há pretensão de reconciliar o crescimento econômico e a proteção ambiental, incluindo a preocupação social de distribuição de renda mais homogênea entre nações, para alcançar melhor gestão do ambiente comum, em que é ressaltado o papel governamental (CLEGG, HARDY et al., 1996).

A Lei no 6.938/1981, presente em nossa legislação, dita a definição de meio ambiente como "o conjunto de condições, leis, influências e interações de ordem física, química e biológica, que permite, abriga e rege a vida em todas as suas formas" (art. 3. ', I). Além disso, o meio ambiente é definido como de uso comum do povo (art. 2. ${ }^{\circ}$, I) e essencial para sadia qualidade de vida (art. 6. ${ }^{\circ}$, II). Segundo Oliveira, o conceito é dividido em: (i) Meio ambiente natural: flora, fauna, elementos da biosfera; (ii) Meio ambiente cultural: patrimônio cultural, artístico, etnográfico, paisagístico; (iii) Meio ambiente artificial: espaço urbano, as cidades e seus espaços abertos e fechados; e (iv) Meio ambiente laboral: o que é vinculado à saúde do trabaIhador (OLIVEIRA, 2009).

Apesar do caráter antropocêntrico ao se tratar do conceito de meio ambiente como um direito do ser humano instrumentalizando-o, a preservação do equilíbrio do ambiente natural permeia grande parte do documento de uma forma muito mais expressa do que qualquer outra Constituição anterior, o que lhe garantiu um caráter ambientalista inédito. É importante destacar, contudo, que 
nossa legislação ambiental atual é resultado de uma longa evolução na política ambiental brasileira, como descreveremos no item a seguir.

\section{O SURGIMENTO DO DIREITO AMBIENTAL,} A POLÍTICA AMBIENTAL BRASILEIRA E A
CONSTITUIÇÃO DE 1988

O incessante desenvolvimento econômico gerado pela Revolução Industrial minimizou, ou até negligenciou, a consideração da esfera ambiental nos planos de desenvolvimento durante muitos anos. Os aparentes benefícios do progresso transformaram-no em um "mal necessário", mesmo diante da poluição e dos impactos ambientais visíveis por ele causados (GOLDENBERG \& BARBOSA, 2004). Com o fim da Segunda Guerra Mundial, a confirmação da capacidade destrutiva do homem, aliada a fatores como o acentuado processo de industrialização e de desenvolvimento de novas tecnologias, o crescimento demográfico acelerado e a percepção de finitude dos recursos naturais, tornaram crescente a vontade e a necessidade de preservação do planeta e de seus recursos. Nesse sentido, o problema ambiental tornou-se, em nível mundial, objeto de constitucionalização.

Tendo como plano de fundo os primeiros movimentos voltados à militância pelo equilíbrio da vida no planeta, como as publicações do livro "Primavera Silenciosa", de Rachel Carson, em 1962 (CARSON, 2002), que dava voz ao perigo que os pesticidas representavam à vida, e do relatório "Os Limites do Crescimento", do Clube de Roma, em 1971 (MEADOWS et al., 2004), que modelava efeitos catastróficos para o ritmo de crescimento demográfico e industrial da época, a ONU (Organização das Nações Unidas) organizou a primeira Conferência das Nações Unidas sobre o Meio Ambiente Humano, em Estocolmo, no ano de 1972. Durante a Conferência, foram redigidos 26 princípios que configuram a Declaração Universal do Meio Ambiente (Ministério do Meio Ambiente, 2017) documento que delegou a cada país a responsabilidade de legislar de forma a proteger seus recursos naturais, e foi assim que o ramo ambiental surgiu nas Ciências Jurídicas em âmbito internacional (FARIAS, 2006). Ressalta-se que leis de proteção ambiental existiam há muitos anos, porém não contavam com referenciais e objetivos traçados internacionalmente.

A política ambiental brasileira se estruturou como resposta às pautas ambientais internacionais, e surgiu de forma tardia entre as demais políticas setoriais do país. $\mathrm{O}$ principal fator que motivou este fato, segundo Moraes e Turolla (2004), foi o processo de industrialização e urbanização no Brasil que se desenrolou durante as décadas de 1930 a 1970, e especialmente com a implantação do
II Plano Nacional de Desenvolvimento em 1974. O desenvolvimento econômico do país não dialogava com as práticas de proteção do meio ambiente, e a posição do Brasil frente às questões ambientais levantadas internacionalmente foi tomada de forma a atendê-las sem que o desenvolvimento econômico da nação fosse sacrificado. Desta forma, a política ambiental nacional não foi concebida sob uma ótica integradora, desvalorizando o potencial da postura sustentável como fator de desenvolvimento.

Apesar dos fatos supracitados, não se podem negar as diversas iniciativas do Estado para atender à demanda ambiental. Nos anos 1970, o Brasil começou a desenvolver instrumentos de política ambiental de fato, tendo como motivadores os reflexos da Conferência de Estocolmo na política internacional. Ainda que conflitante com seus planos de desenvolvimento, o país adentrava no tema meio ambiente, criando órgãos específicos para a área, como a Secretaria Especial do Meio Ambiente (SEMA). Segundo Milaré (2004), a preocupação com o meio ambiente em termos de legislação, caracterizada pela definição de conceitos, princípios, objetivos e instrumentos para a sua defesa, teve início na década de 1980, com sua importância reconhecida pela Lei no 6.938/81, que estabeleceu a Política Nacional do Meio Ambiente:

[...] tem por objetivo a preservação, melhoria e recuperação da qualidade ambiental propícia à vida, visando assegurar, no País, condições ao desenvolvimento sócioeconômico, aos interesses da segurança nacional e à proteção da dignidade da vida humana" (Lei n 6.938/81, art. 2) [1]

O governo brasileiro criou estrutura pública para a regulamentação das questões ambientais, como a criação do Conselho Nacional do Meio Ambiente (CONAMA), órgão consultivo e deliberativo, e do Sistema Nacional do Meio Ambiente (SISNAMA). Em 1985, a Lei no 7.347 instituiu a Ação Civil Pública como instrumento de defesa específico para a defesa do meio ambiente (LIMA, 2014), para que efetivamente os danos chegassem ao Poder Judiciário. Após o Congresso de Viena, ainda no ano de 1985, uma postura preventiva começou a figurar no pensamento ambiental internacional e nacional. Mecanismos como a AIA (Avaliação de Impacto Ambiental, que surgiu nos EUA ainda em 1969) se tornaram condição a ser cumprida para autorização de projetos de caráter nocivo ao meio ambiente.

Contudo, a primeira Lei Maior brasileira a sistematizar a questão do meio ambiente foi a Constituição Federal de 1988, tendo em vista os princípios que se aplicam aos assuntos ambientais expressos e implícitos difundidos pelo 
Texto Maior, tornando este documento essencialmente ambientalista (BULOS, 2003). Promulgada em 5 de outubro de 1988, a Constituição Federal foi redigida em um contexto de mudanças significativas no trato do meio ambiente. Como reflexo disso, seu conteúdo apresenta um expressivo avanço no trato das questões ambientais, como a discussão explícita do tema no documento e na declaração do dever, por parte do Poder Público e da coletividade, de defender e preservar o meio ambiente para as gerações presentes e futuras.

Com as mudanças trazidas pela Constituição Federal de 1988, o Direito Ambiental brasileiro ganhou mais expressividade, uma vez que muitos de seus princípios encontram-se expressos no documento. Esses princípios têm valor normativo e, hierarquicamente, possuem maior valor que qualquer regra, servindo de base para a legislação ambiental brasileira. Na visão de Farias (2006), destacam-se com maior expressividade os seguintes princípios:

(i) Princípio da Prevenção: qualquer dano ambiental deve ser evitado, tendo em vista sua impossível reparação. (ii) Princípio da Precaução: se não houver a certeza de que as alterações não causarão danos ambientais, o princípio prevê a vedação de intervenções no meio ambiente. (iii) Princípio do Poluidor-Pagador: os custos do uso de recursos ambientais devem ser direcionados a quem os utiliza, de forma não abusiva. (iv) Princípio da Responsabilidade: os causadores da degradação ambiental são responsáveis e obrigados a arcar com as responsabilidades pelo dano causado. (v) Princípio da Gestão Democrática: garante o direito à informação e à participação na elaboração das políticas públicas ambientais ao cidadão, assegurando mecanismos que efetivam o princípio. (vi) Princípio do Limite: fixa parâmetros mínimos a serem observados em caso de emissão de partículas, ruídos, sons, destinação de resíduos sólidos, hospitalares e líquidos a fim de manter o desenvolvimento sustentável (FARIAS, 2006).

Em 1989, a extinção do SEMA deu lugar ao surgimento do IBAMA (Instituto Brasileiro do Meio Ambiente e dos Recursos Naturais Renováveis, instituído pela Lei n 7.735), e em 1992, foi criado o Ministério do Meio Ambiente, dos Recursos Hídricos e da Amazônia Legal (MMA) pela Lei no 8.490, que fica responsável pela Política Nacional do Meio Ambiente. Paralelo a estes acontecimentos, em âmbito mundial, em 1987 foi organizado o Relatório de Brundtland, intitulado "Nosso Futuro Comum", que pela primeira vez discutia o desenvolvimento sustentável como o futuro para a humanidade. Este evento, como diz Souza (2005), "significou para o Brasil ter que enfrentar a crise ambiental e ao mesmo tempo retomar o desenvolvimento, fortalecendo a democracia e a estabilidade da economia", o que mostrou a necessidade da redefinição de diversos pontos na política ambiental do país na época.

Mais tarde, com o conceito de desenvolvimento sustentável sendo discutido internacionalmente e com o intuito de iniciar sua integração às políticas ambientais dos países, ocorre a ECO-92. Na conferência, os seguintes acordos foram assinados: a Agenda 21, a Declaração do Rio para o Meio Ambiente e Desenvolvimento, Convenções do Clima e da Biodiversidade e a Declaração de Princípios para as Florestas. A Agenda 21 ganhou destaque na medida em que estabeleceu compromissos para a preservação do meio ambiente e dispôs sobre ações sociais e econômicas. A Agenda 21 brasileira buscava integrar o meio ambiente e o espaço urbano, com o intuito de transmitir políticas ambientais nos diversos níveis de poder do país, em uma tentativa de resposta à crise política ambiental no Brasil. Em 1998, foi aprovada a Lei de Crimes Ambientais no Brasil, que significou um grande avanço para os instrumentos de penas ambientais. A lei foi considerada uma das mais avançadas do mundo, na medida em que atividades que comprometessem o meio ambiente poderiam ser punidas civil, criminal e administrativamente.

Em 2002, houve a Rio+10 que dava continuidade às pautas da ECO-92. Seus impactos, entretanto, são discutíveis, uma vez que não houve grandes reflexos nas políticas ambientais brasileiras e internacionais decorrentes da conferência, mas sim a tomada de medidas ainda em resposta à ECO-92. Fora da influência do contexto legal internacional, ainda que pontuais, verificaram-se, no Brasil, algumas mudanças com relação ao assunto, como o ordenamento de políticas públicas ambientais na área territorial, uma vez que o patrimônio ambiental brasileiro foi por vezes desgastado pela exploração inadequada.

Em termos de legislação brasileira, pode-se afirmar que a mais recente discussão incorporada aos textos legais foi o novo Programa Nacional de Resíduos Sólidos (PNRS), que representa a tentativa de adaptar o país ao princípio de responsabilidade compartilhada pelo ciclo de vida dos produtos (STRAIOTO e FIGUEIREDO, 2011) Instituída pela Lei no 12.305, em 02 de agosto de 2010, o programa conta com importantes conceitos e instrumentos que proporcionam ao Brasil a possibilidade de enfrentar os problemas advindos do manejo inadequado de seus resíduos sólidos, como a própria definição e aplicação estratégica da logística reversa:

Instrumento de desenvolvimento econômico e social caracterizado por um conjunto de ações, 
procedimentos e meios destinados a viabilizar a coleta e a restituição dos resíduos sólidos ao setor empresarial, para reaproveitamento, em seu ciclo ou em outros ciclos produtivos, ou outra destinação final ambientalmente adequada. (Lei no 12.305, art. 30, inciso XII) [2]

Estão presentes, entre seus princípios, o desenvolvimento sustentável (art. 6०, inciso IV), a responsabilidade compartilhada pelo ciclo de vida dos produtos (art. $6^{\circ}$, inciso VII), o reconhecimento do resíduo sólido reutilizável e reciclável como um bem econômico e de valor social (art. $6^{\circ}$, inciso VIII), que exemplificam diretrizes gerais importantes, fundamentando uma nova postura do país frente a um dos maiores problemas mundiais atuais.

Pode-se afirmar que no Brasil encontramos, na prática, um aparato institucional regulatório desenvolvido, mas que conta com falhas no que se diz respeito à integração do meio ambiente aos setores a ele relacionados, o que corrobora para o descumprimento de muitas metas traçadas na própria política ambiental do país (SOUZA, 2009). A elisão na legislação ambiental brasileira quanto às necessidades de sustentabilidade nos processos produtivos leva à irresponsabilidade das empresas para com o tema, de forma que a natureza é constantemente exaurida pelo denso processo industrial e tecnológico do país. Contudo, esta realidade vem sendo contornada, mesmo que lentamente, por importantes ações do governo, como pode ser visto com a implementação da Política Nacional de Resíduos Sólidos.

\section{A SUSTENTABILIDADE COMO FATOR NECESSÁRIO NAS EMPRESAS E O PAPEL DO DESIGNER NA QUEBRA DO PARADIGMA: PRODUÇÃO INDUSTRIAL E MEIO AMBIENTE}

Segundo Roy (2006), a sustentabilidade se conceitua a partir de três pilares: ambiental, econômico e social, de forma que um pilar não existe sem o outro. Nesse sentido, percebe-se a sustentabilidade sob uma ótica integradora, em que a preservação do meio ambiente se equipara ao desenvolvimento humano social e econômico. $\mathrm{Na}$ intercomunicação dessas áreas, percebemos que nosso sistema atual de produção e consumo está por entrar em colapso. Produzimos muito mais do que somos capazes de consumir, consumimos de forma irresponsável e inconsciente e sobrecarregamos o meio ambiente com quantidades expressivas de resíduos produzidos dia após dia. Percebe-se a urgência em agir de forma pró-ativa visando evitar a sobrecarga do planeta, visto que apenas reparar os danos que causamos para manter um bom "ritmo de desenvolvimento" não é resposta suficiente para a construção de um futuro sustentável.
Segundo o CEBDS (Conselho Empresarial Brasileiro para o Desenvolvimento Sustentável, 2015),

a longevidade das organizações exige que seu desenvolvimento seja sustentável e a nova sociedade exige inovação. Adotar o olhar da sustentabilidade nos departamentos vinculados à inovação torna-se, então, uma questão de sobrevivência. (CEBDS, 2015) [3]

Percebe-se, aqui, que a sustentabilidade e a inovação não são mais fatores quaisquer a serem agregados na gestão e concepção de produtos em empresas, mas sim questões que se tornaram vitais para a sobrevivência delas, na medida em que a sociedade já exige a inovação e a preservação do equilíbrio planetário como requisitos básicos de uma organização respeitável e responsável.

Entre os conceitos de sustentabilidade e inovação, o último ainda é mais comentado. Graças ao nível sem precedentes de empresas atuando no mercado, a inovação ganha lugar como uma estratégia poderosa no mundo dos negócios. O fato é que, se é preciso inovar, tem-se de adotar o design (NEUMEIR, 2010 apud STRAIOTO e FIGUEIREDO, 2014). Entende-se por inovação a busca bem sucedida por novas ideias, abordagens e soluções, e o design torna-se instrumento básico para esta busca na medida em que a profissão se pauta na solução de problemas de forma eficiente ao consumidor, levando em consideração as diversas áreas em que o produto se expressa. Neste sentido, vê-se a união da profissão com a necessidade de incorporar a sustentabilidade nos processos de produção das empresas, tanto para garantir o fator competitivo quanto para minimizar os impactos delas no meio ambiente, como uma solução eficaz para o dilema.

Segundo Lay,

o designer quando voltado à sustentabilidade deve possuir uma visão holística e mais ampla do que a utilizada hoje. Não deve apenas tentar solucionar uma necessidade apreendida de um cliente ou um grupo, mas também, atentar para cada uma das etapas nas quais seu projeto influenciará. Por exemplo, nas etapas do ciclo de vida de um produto tanto na extração da matéria-prima como em um futuro uso dos componentes, o chamado "do berço ao berço". (LAY, 2011 apud BERTONI, 2012, p. 71) [4]

Conforme Bertoni,

o papel de designer, por conseguinte, é educar os consumidores por meio de projetos realizáveis de maneira consciente. Ainda, dentro 
do nível financeiro, deve ocorrer a geração de uma economia que possibilite boas condições de vida ao homem, sem ferir o ecossistema e o desenvolvimento das populações, promovendo ainda, um intercâmbio de informações. (BERTONI, 2012, p. 61) [5]

Esta importância do papel do designer foi destacada já na década de 1960 por Papanek, que afirmou:

em uma época de produção em massa, quando tudo deve ser planejado e projetado, o design tornou-se a ferramenta mais poderosa com a qual o homem molda suas ferramentas e ambientes (e, por extensão, a sociedade e ele mesmo). (PAPANEK, 1963) [6]

Com o poder de moldar a produção industrial, é função do designer refletir sobre o impacto de suas ideias, levando em conta o tempo necessário para que o ambiente assimile e seja capaz de conviver com elas de forma harmônica.

Projetar produtos de baixo impacto, pensando em seu ciclo de vida de uma forma cíclica, diminuindo a quantidade de matéria-prima necessária e de processos produtivos envolvidos, são pontos de suma importância na concepção e no desenvolvimento de produtos, e que, por força de legislação, lentamente estão passando a ser condicionantes de projeto, como foi comentado na seção anterior.

O design tem o poder de reverter este déficit que encontramos entre a produção industrial e a preservação e regeneração do meio ambiente, pois, como destaca Penna:

o Design está intimamente ligado ao ciclo de vida dos produtos. Tudo deve ser pensado, desde a extração da matéria prima - se é sustentável -, passando pelo transporte até a fábrica - se a distância gera impacto ambiental com o consumo de combustíveis fósseis - e pela fabricação - uso da água e da energia, solução para insumos, armazenagem, embalagem, distribuição, logística reversa -, até o consumo - preocupação com o descarte ecológico. São questões importantes que o Design ajuda a solucionar, portanto ajuda no desenvolvimento sustentável do país. (PENNA, 2016, p. 47) [7]

Quando visto como uma ferramenta que pode garantir a sustentabilidade de processos e produtos, o profissional comprometido com seu trabalho de forma ética e responsável pode se tornar um indivíduo capaz de promover inúmeras saídas para a crise ambiental em que estamos inseridos. Este profissional também pode se tornar o próprio fiscal de uma produção voltada ao consumo consciente e sustentável.

No entanto, para que esta forma de atuar ocorra, é preciso uma sólida base de conhecimentos sobre materiais e processos produtivos, além da capacidade de assimilar conhecimentos de outras áreas, como o direito ambiental discutido no item anterior. Um profissional com este perfil deve ter uma formação ampla e bem alicerçada, necessidade que é confrontada pela realidade em que o profissional está inserido no país.

No Brasil, a profissão de designer não é reconhecida pelo Ministério da Educação e Cultura, o que significa que pessoas não qualificadas podem atuar no mercado de trabalho se intitulando como designers, mas sem o mínimo de conhecimento sobre as responsabilidades e as questões éticas que envolvem a profissão. Somado a isto, os profissionais da área constantemente enfrentam o desconhecimento sobre as possibilidades de atuação do designer ou a má compreensão desta atividade, limitando-a e reduzindo-a, como Penna (2016) ressalta ao dizer: "mas ainda pensam que [Design] é coisa de estilo, ou estética, ou apenas um vernizinho na superfície!" [8]. Deste modo, o profissional, que poderia se tornar um aliado para o alcance do desenvolvimento sustentável no país tem sua atuação restringida, o que pode resultar na desvalorização de seu trabalho.

\section{CONSIDERAÇÕES FINAIS}

Um meio ambiente equilibrado, que garanta a manutenção da qualidade de vida para as gerações futuras, configura uma das questões mais relevantes a ser solucionada em qualquer discussão que se paute em sustentabilidade. Apesar de não ser um problema atual, o tema ganhou força nas últimas décadas sendo foco de diversas reflexões e ações, inclusive com a discussão sobre como o ser humano se vê inserido no meio ambiente natural e como isto reflete no próprio conceito de, como foi comentado no item 3.

Há diversos mecanismos que podem contribuir para o desenvolvimento de um equilíbrio entre o ser humano e o meio ambiente, como o poder regulatório das legislações, que norteiam a ação humana sobre os recursos naturais do planeta, discutidos, principalmente, no item 4.

No Brasil, a política ambiental e a legislação pertinente podem ser consideradas avançadas, porém sua instauração foi tardia, devido em parte ao processo de industrialização, que também ocorreu num tempo defasado em relação a outros países, e isto resultou em necessidades não solucionadas. Desta forma, observa-se que a política ambiental nacional estrutura-se sobre parâmetros normativos internacionais que, em alguns momentos históricos importantes, não alinharam-se às políticas setoriais do 
país. Porém, cada vez mais esta legislação é aprimorada para que esteja em cosonância com as pressões e preocupações ambientais apropriadas por uma parcela cada vez maior da sociedade, conforme se buscou descrever.

Neste contexto, o profissional da área do design é inserido como o aplicador de métricas de sustentabilidade na produção de produtos, em um panorama no qual as empresas percebem o valor da sustentabilidade como um fator competitivo, ou são obrigadas a aceitá-lo por força de legislação. Além disso, destaca-se o design como fonte de inovação e responsabilidade com o tema na produção. Vale dizer que, a própria carência na regulamentação da profissão de projetistas de produto pode atrapalhar o papel propulsor e fiscalizador do designer no cenário de transformação do fluxo linear de extração, produção e consumo, conforme comentado no item 6.

O objetivo que norteou esta parte inicial do estudo foi investigar a legislação e textos produzidos por profissionais de direito, e isto mostrou a importância da compreensão e diálogo multidisciplinar para que mudanças abrangentes sejam alcançadas. A legislação precisa de meios para ser posta em prática efetivamente no cenário atual, e os projetistas têm o conhecimento para planejar e mostrar como isto pode ocorrer na prática. Contudo, o conhecimento e a competência necessários para o desenvolvimento de soluções ambientalmente orientadas são alcançados com uma formação sólida, proporcionada por meio de exigências advindas da regulamentação da profissão.

\section{REFERÊNCIAS}

BERTONI, A. S. “Estudo dos sistemas de certificação sustentável para residências: de que modo as certificações podem servir como ferramenta de auxílio voltada à sustentabilidade sob o ponto de vista do papel ético do designer". 152 f. Dissertação de Mestrado em Design UniRitter, Porto Alegre. 2012. p. 61

BRASIL, Lei n 6.938, de 31 de agosto de 1981, lei da política nacional do meio ambiente, disponível em: <ww. planalto.gov.br>, acessado outubro de 2016, art. $2^{\circ}$.

BRASIL, Lei n 12.305, de 02 de agosto de 2010, lei da política nacional de resíduos sólidos, disponível em: <ww.planalto.gov.br>, acessado novembro de 2016, art. 30, inciso XII.

BULOS, Uadi Lammêgo. Constituição Federal anotada / Uadi Lammêgo Bulos. - 5. ed. rev. e atual. até a Emenda Constitucional n. 39/2002 - São Paulo: Saraiva, 2003.
CAPRA, F. A Teia da Vida: uma nova compreensão científica dos sistemas vivos. São Paulo: Cultrix. 1998. 256 p.

CARSON, R. Silent Spring Silent, 1962. Boston: Houghton Mifflin. 2002. 378p.

CARVALHO, I. C. M. Educação ambiental: a formação do sujeito ecológico. 2. ed. São Paulo: Cortez, 2006. (Coleção Docência em formação).

CEBDS, Como inserir a sustentabilidade em seus processos - Inovação, Rio de Janeiro, 2015, p 7. Disponível em: $<$ http://cebds.org/publicacoes/guias-de-sustentabilidade-inovacao/\#.WM7JRPnyvlU>. Acesso em: novembro, 2016.

CLEGG, S., C. HARDY, et al. Handbook of organization studies. London; Thousand Oaks: Sage Publications. 1996. xxix, $730 \mathrm{p}$.

FARIAS, Talden Queiroz. Evolução histórica da legislação ambiental. In: Âmbito Jurídico, Rio Grande, X, n. 39, mar 2007. Disponível em: < http://www.ambitojuridico.com.br/site/index.php?n_link=revista_artigos_leitura\&artigo_id=3845 >. Acesso em 22 de setembro de 2016.

FARIAS, Talden Queiroz. Princípios gerais do direito

ambiental. In: Âmbito Jurídico, Rio Grande, IX, n. 35, dez 2006. Disponível em: <http://www.ambito-juridico.com. br/site/index.php?n_link=revista_artigos_leitura\&artigo_id=1543>. Acesso em 22 de setembro de 2016.

FERREIRA, Aurélio Buarque de Holanda. Dicionário Aurélio da Língua Portuguesa. Curitiba: Positivo, 2010.

GOLDENBERG, J.; BARBOSA, L. M. A legislação ambiental no Brasil e em São Paulo. In: Revista Eco 21, Ano XIV, Edição 96, Novembro 2004. Disponível em: < http:// www.eco21.com.br/textos/textos.asp?ID=954 >. Acesso em 18 de agosto de 2016.

HAWKEN, P., A. B. Lovins, et al. Natural capitalism: creating the next industrial revolution. Boston: Little, Brown and Co. 1999. xix, 396 p.

JACQUES, J. “Estudo de Iniciativas em Desenvolvimento Sustentável de Produtos em Empresas Calçadistas a partir do Conceito Berço ao Berço". Tese de doutorado. Engenharia de Produção, Universidade Federal do Rio Grande do Sul, Porto Alegre 2011. 
LAY (2011) apud BERTONI, A. S. "Estudo dos sistemas de certificação sustentável para residências: de que modo as certificações podem servir como ferramenta de auxílio voltada à sustentabilidade sob o ponto de vista do papel ético do designer". 152 f. Dissertação de Mestrado em Design - UniRitter, Porto Alegre. 2012, p. 71.

LIMA, Francisco Arnaldo Rodrigues de. $\mathbf{O}$ direito ambiental nas constituições do Brasil: um breve relato de sua construção histórica e a tese do artigo 225 CF/88 como cláusula pétrea. In: Âmbito Jurídico, Rio Grande, XVII, n. 122, mar 2014. Disponível em: <http://ambito-uridico.com.br/site/?n_link=revista_artigos_leitura\&artigo_id=14555>. Acesso em: setembro, 2016.

McDONOUGH, W. E. BRAUNGART. M. Cradle to Cradle: remaking the way we make things. New York: North Point Press. 2002. 193 p.

MEADOWS, D. H., J. RANDERS, et al. The limits to growth: the 30-year update. White River Junction, Vt: Chelsea Green Publishing Company. 2004. xxii, 338 p.

MILARÉ, Edis. Direito do ambiente. 3 ed. São Paulo:

MINISTÉRIO DO MEIO AMBIENTE. Disponível em: http://www.mma.gov.br/estruturas/agenda21/_arquivos/ estocolmo.doc). Acesso em: março, 2017.

MORAES, S. R. R.; TUROLLA, F. A. Visão Geral dos Problemas e a Política Ambiental no Brasil. Revista: Informações Econômicas, São Paulo, v.34, n.4, abr. 2004.

OLIVEIRA, Fabiano Melo Gonçalves de. Difusos e Coletivos: direito ambiental - São Paulo: Editora Revista dos Tribunais, 2009. (Elementos do Direito, v.15).

PAPANEK, V. Design for the Real World. 2. ed. GrãBretanha: Thames \& Hudson, 1995. Prefácio.

PENNA, Patrícia. Esse tal de Design! Revista Pensar Verde, Brasília - DF, no 16, ano 4, março/abril/maio de 2016. Página 44. Disponível em: <https://issuu.com/pensarverde/ docs/pensarverde16>. Acessado em: dezembro, 2016, p. 47

PESSOA, F. M. G.; BARRETO, P. C.. Do direito fundamental ao meio ambiente ecologicamente equilibrado à concepção do direito do meio ambiente. Revista

Evocati, no 86, fevereiro de 2013. Disponível em: < http:// www.evocati.com.br/evocati/interna.wsp?tmp_page $=$ interna\&tmp_codigo $=566 \&$ tmp_secao $=22 \& t m p \_t o p i c o=-$ direitoambiental>. Acesso em: outubro, 2016.

RISSATO, D.; SPRICIGO, B. A Política Ambiental no Brasil no Período De 1970-1999. Revista: Ciências Sociais em Perspectiva, Cascavel, Vol. 9 - No 16 - 10 Semestre de 2010.

ROY, R. Products: New Product Development and Sustainable Design. Milton Keynes: The Open University, 2006

SOUSA, A. C. A. de. A evolução da política ambiental no Brasil do século XX. Revista de Ciência Política, n. 26, 2005. Disponível em: <http://www.achegas.net/numero/ vinteeseis/ana_sousa_26.htm>. Acesso em 26/08/2016.

STRAIOTO, R. G. T; FIGUEIREDO, L. F; “Gestão de Design para Sustentabilidade com base na Política Nacional de Resíduos Sólidos: uma Proposta de Integração", In: Anais do $11^{\circ}$ Congresso Brasileiro de Pesquisa e Desenvolvimento em Design [ Blucher Design Proceedings, v. 1, n. 4]. São Paulo: Blucher, 2014. 